\title{
La lúdica, el juego, la matemática y otras áreas del conocimiento
}

\author{
The playful, the game, the mathematics and other areas of \\ knowledge
}

O lúdico, o jogo, a matemática e outras áreas do conhecimento

José Antonio Ardila Amézquita

Especialista en matemática avanzada

Universidad Surcolombiana joseantonioardila@gmail.com

\section{Resumen}

Recordar es vivir dice uno de los tantos dichos populares y en verdad que con este artículo he podido regresar a algunos pasajes de mi infancia y de manera especial, a ciertos años de la escolaridad en mi patria chica Teruel Huila.

Obligatoriamente por decirlo de alguna manera sugiero, dada la experiencia que tuve al estudiar los procesos de enseñanza y aprendizaje de los escolares unas cuantas ideas para llevarlas al aula y proponiendo con ellas iniciar cambios en el ciclo primario fundamentalmente buscando ir eliminando el aprendizaje memorístico de la matemática, mediante la lúdica y el juego soñando con presentar a los chicos una infancia llena de sueños, diversión, felicidad y aprendizajes llenos de emoción y para toda la vida.

Palabras claves: Juego, lúdica, sistema de numeración Indu-arábigo, contar, operaciones y propiedades, ábaco abierto.

\section{Abstract}

To remember is to live says one of the many popular sayings and in truth that with this article I have been able to return to some passages of my childhood and in a special way, to certain years of schooling in my homeland Teruel Huila. 
Obligatory to say it in some way I suggest, given the experience I had when studying the teaching and learning processes of the students a few ideas to take them to the classroom and proposing with them to initiate changes in the primary cycle fundamentally seeking to eliminate the rote learning of the mathematics, through play and the game dreaming of presenting children with a childhood full of dreams, fun, happiness and learning full of emotion and for life.

Keywords: Game, playful, numbering system Indu-arabic, count, operations and properties, open abacus.

\section{Resumo}

Lembrar é viver, diz um dos muitos provérbios populares e, na verdade, com este artigo, pude retornar a algumas passagens da minha infância e, de uma maneira especial, a certos anos de escolaridade em minha terra natal Teruel Huila.

É obrigatório dizer que de alguma forma eu sugiro, dada a experiência que tive ao estudar os processos de ensino e aprendizagem dos alunos algumas idéias para levá-los para a sala de aula e propor com eles para iniciar mudanças no ciclo primário fundamentalmente buscando eliminar a aprendizagem mecânica do matemática, através do brincar e do jogo sonhando em apresentar crianças com uma infância cheia de sonhos, diversão, felicidade e aprendizado cheios de emoção e pela vida.

Palavras-chave: Jogo, brincalhão, sistema de numeração Indu-arábica, contagem, operações e propriedades, ábaco aberto.

Por el lugar de origen perfectamente recuerdo a que huele la tierra, que aroma tiene el sudor de un animal, a que sabe la verdadera lactosa, cual es el olor a estiércol, que se percibe al sentir la fatiga del caballo, puedo sin ningún temor pero más bien con alegría decirles que, desde los primeros momentos que pasé en la escuela, vi como el profesor enseñaba a los niños a leer, escribir y contar enfurecido porque no aprendían tan rápido como él deseaba. No entendía que algo tan lindo se enseñaba en la escuela. Ya lo había aprendido jugando, lo había vivido escuchando e imitando los sonidos de la naturaleza y el de los animales, el ambiente era rico sobre todo se respiraba libertad (ver imagen, escuela de la vida) ¿Por qué mis compañeros lo hacían con lágrimas en los ojos? , ¿Por qué eso de la letra con sangre entra?, ya no respiraba tan natural como en el anterior entorno, pero era la escuela y allí existían otros parámetros a seguir, la disciplina, 
la autoridad, a veces exagerada y además se entendía por qué un niño abandonaba la escuela, el miedo terminaba matándolo, el juego solo se limitaba al recreo pero eso era muy diferente a jugar.

La infancia la considero como todos los olores que se quedan pegados a los sueños, el alfabeto de la piel, los presentimientos que nunca llegan a convertirse en palabras, la música de una canción,

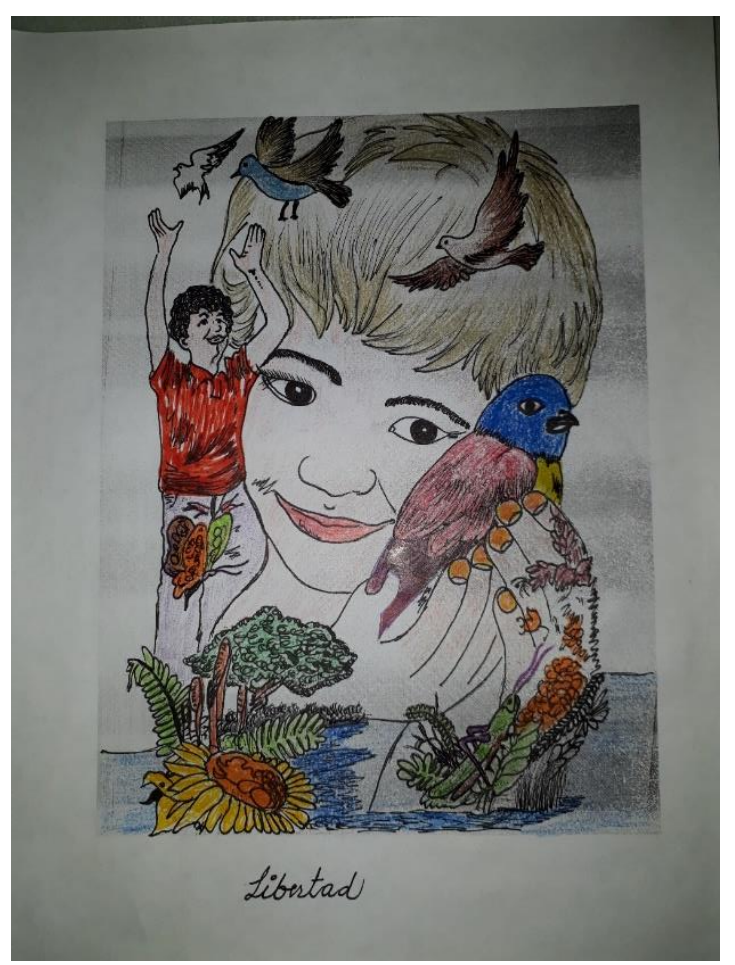

Ilustración 1 Escuela de la Vida

el juego que nos proporciona la naturaleza, en fin, no quisiera dejar la infancia y deseo que la escuela debiera ser obligatoriamente su continuidad, desafortunadamente nuestro desarrollo intelectual, muere rápidamente, porque ella también es una manera de aprender a perder la alegría. Es una canción que quedó atrapada entre las paredes, el corredor y el patio de recreo, poco a poco vamos dejando de lado las preguntas y las palabras, pero al final hay algo muy hermoso, recordamos con agrado el aroma de la escuela.

Bien lo decía Einstein. "Lo importante es no dejar de hacer preguntas".

Los salones son amplios y con el piso de cemento. Los pupitres grandes, algunos con cuatro y otros con tres puestos, un olor a goma de borrador, a tinta azul, a papel caliente, a cachorro recién bañado; los cuadernos reposan sobre los asientos. Algunos abiertos todavía, registrando la prisa de manos que dejaron una palabra a medio escribir; dibujos recién iniciados y sin color; en el tablero la palabra silencio; al lado, el esquema de muchas operaciones matemáticas enumeradas, trazadas con una letra fuerte y bien delineada.

A lo lejos, el murmullo de gritos, risas, voces, como el sonido de un río feliz. De pronto, una campana rompe el bullicio. "El recreo ha concluido", con estas últimas palabras Cordero (1997. p. 50) describe la escuela (ver imagen, ambiente tradicional). 


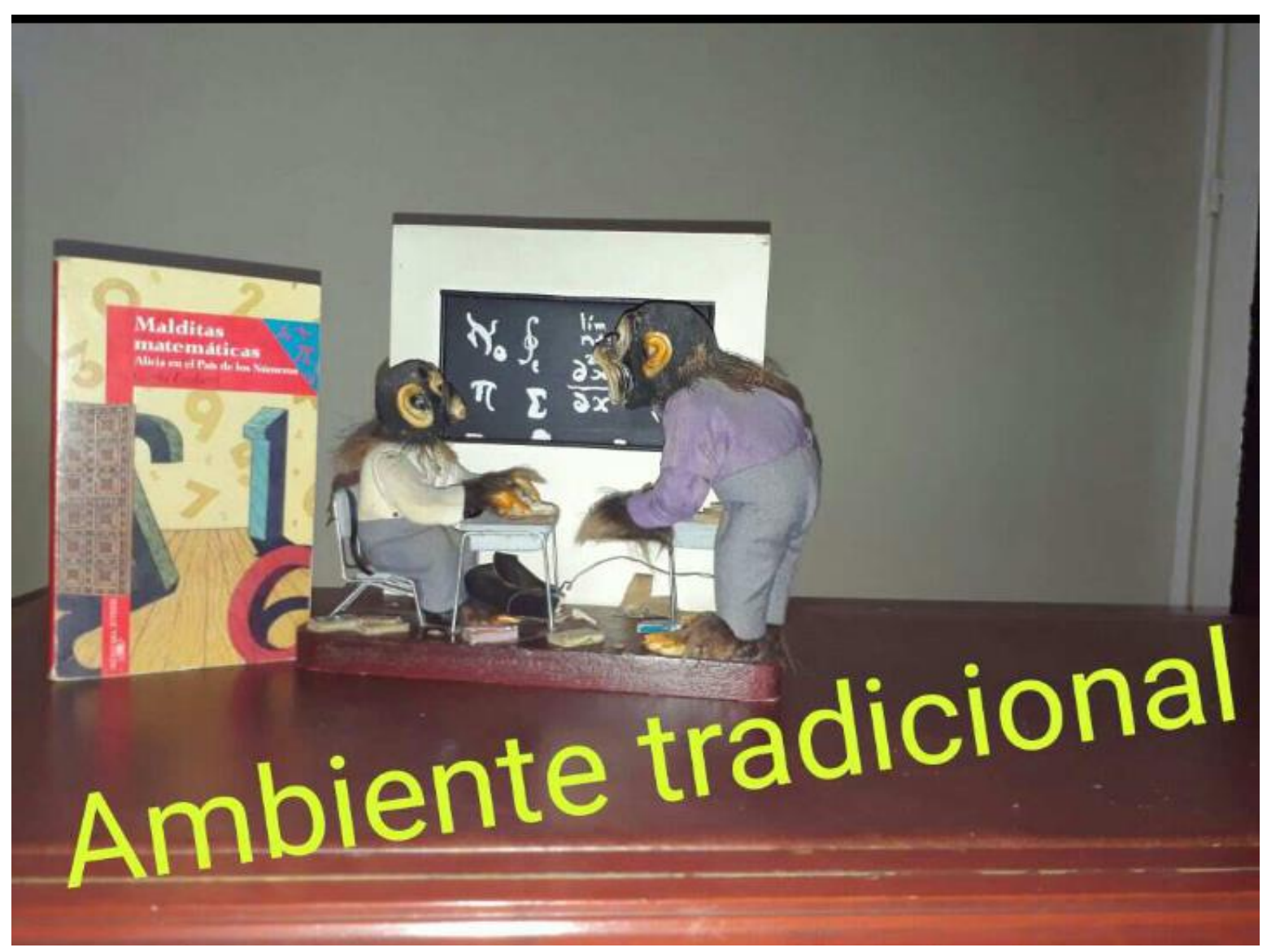

Ilustración 2 Ambiente Tradicional

En las siguientes líneas, recurro entre otras cosas a algunos intelectuales que hablan de la lúdica y del juego en especial.

El juego es una actividad que a todo ser humano le gusta y disfruta con ella, es más, los animales también lo hacen y para no ir más lejos tenemos dos de ellos domésticos: el perro y el gato, Juegan solos, juegan con su compañero, juegan con su amo, juegan y juegan, durante toda su vida, al igual que el hombre, no es solo el juego una actividad relacionada con los niños, empieza tal vez en el año cero o muy cerca de él antes o después, ese no es el problema, lo fundamental es que siempre juega y debería hacerlo toda la vida.

\section{Características del juego}

Según Johan Huizinga (1990 p. 20 27) en su libro Homo Ludens, las características del juego son:

1. Es libre, es libertad.

2. El juego no es la vida corriente o la vida propiamente dicha. Cualquier juego puede absorber por completo, en 
cualquier momento, al jugador.

3. Se juega dentro de límites de tiempo y de espacio. Agota su curso y su sentido dentro de sí mismo. El juego comienza y en determinado momento, ya se acabó.

4. El juego cobra inmediatamente sólida estructura como forma cultural. Una vez que se ha jugado permanece en el recuerdo como creación o como tesoro espiritual, es transmitido por tradición y puede ser repetido en cualquier momento, ya sea inmediatamente después de terminado, como un juego infantil, una partida de bolos, una carrera, o trascurrido un largo tiempo.

5. La posibilidad de repetición del juego constituye otra de sus propiedades fundamentales. En casi todas las formas altamente desarrolladas de juego los elementos de repetición, el estribillo, el cambio en la serie, constituyen algo como la cadena y sus eslabones diversos.

6. Dentro del campo del juego existe un orden propio y absoluto. La desviación más pequeña estropea todo el juego, le hace perder su carácter y lo anula. El juego oprime y libera, el juego arrebata, electriza, hechiza. Está lleno de dos cualidades más nobles que el hombre puede encontrar en las cosas y expresarlas: ritmo y armonía.

7. En el juego aparece un elemento importante también, él es la tensión, y esto quiere decir: incertidumbre, azar. Es un tender hacia la resolución. Con un determinado esfuerzo, algo tiene que salir bien. Este elemento ya se encuentra en el niño de pecho cuando trata de aprehender con sus manitas, es un gato cuando juega con algo que ruede, en una niña cuando lanza y recoge la pelota. En esta tensión se ponen a prueba las facultades del jugador: su fuerza corporal, su resistencia, su inventiva, su arrojo y su aguante.

8. Cada juego tiene sus propias reglas, estas son obligatorias y no permiten duda alguna. En cuanto se traspasan las reglas se deshace el mundo del juego. Se acabó el juego. El jugador que infringe las reglas del juego o se sustrae a ellas es un aguafiestas o un estropea- juegos.

9. El juego es una lucha por algo o una representación de algo. En la vida del niño la exhibición está ya muy llena de figuración. Se copia algo, se presenta algo en más bello, sublime o peligroso de lo que generalmente es. Si se es príncipe o padre o bruja maligna o tigre. El niño se pone tan fuera de sí que casi cree que "lo es" de verdad, sin perder, sin embargo, por 
completo, la conciencia de la realidad normal.

10.El juego infantil posee de por si la forma lúdica en su aspecto más puro.

Lo que nos brinda esta descripción que hace Huizinga, no debe quedarse en un listado de características, es solo un comienzo para reconocer que el juego es tal vez tan importante como la vida misma ahí tenemos, un gran potencial para reestructurar nuestras labores académicas, ánimo profesores.

Carlos Alberto Jiménez V. (1996), en su libro: La lúdica como experiencia cultural, enfatiza: "la actividad lúdica constituye el potenciador de los diversos planos que configuran la personalidad del niño. El desarrollo sicosocial (como se denomina al crecimiento), la adquisición de saberes, la conformación de una personalidad, son características que el niño va adquiriendo o se va apropiando a través del juego y en el juego. La actividad no es algo ajeno, o un espacio al cual se acude para distensionarse, sino una condición para acceder a la vida, al mundo que nos rodea" (Jiménez, 1996.p. 15).

Y como para tocar aspectos más puntuales y con el respeto a los lectores sobre todo a los docentes del área de la lectoescritura pues, soy maestro de matemáticas. El niño al ingresar a la escuela se encuentra en una edad en la que los sentimientos y fantasías, dominan el pensamiento; así, pues, cuando algo adquiere verdadera importancia para él como aprender a leer y escribir, por ejemplo, él advierte o lo transforma en un proceso mágico o fantástico; de ahí que la visión práctica de la lectura y la escritura como desciframiento no tiene sentido; el necesita aprender con fantasía: los métodos mecanicistas de los textos de lectoescritura que existen en Colombia favorecen más la reproducción de esquemas que la imaginación, la fantasía y la construcción simbólica. El contenido de éstos textos y los métodos que allí aparecen privan a los niños de la recompensa más importante de la lectura; el deseo de comprender más allá del simple reconocimiento de lo que ya sabe; para enseñar a leer se debe propiciar más el encuentro con el significado que con el proceso de descifrar o de repetir como un loro o dicho de otra forma más matemática, de repetir algorítmicamente.

Resumiendo y precisando, para crear una pedagogía de la fantasía, se hace necesario propiciar nuevos espacios significativos para la creatividad y el desarrollo de la autonomía intelectual. Cuando el ser humano es autónomo intelectualmente es un ser libre, no depende de nadie, lo contrario permite calificarlo como un ser sumiso.

Ahora soy atrevido al decir: La lúdica es al desarrollo intelectual como la sabia lo es al árbol. 
Entrando un poco más en materia de los juegos voy a analizar algunos de ellos que se encuentran en nuestro medio, con el objeto de señalar que procesos o conceptos de la matemática están allí presentes, luego que cambios se le podrían hacer, que otros conceptos se pueden hacer aparecer y como rediseñar los juegos para que los niños los puedan jugar en primero, segundo, tercero de primaria y así sucesivamente aumentando su complejidad sin que se pierda el rigor matemático, pero, lo más importante, que no deje de jugar.

Sobran las clases tradicionales, se debe romper con ellas y convertirlas en juegos, fantasías, sueños y no es locura volverlo a decir el juego y la lúdica, son la fuerza hacia el crecimiento intelectual y el día de mañana seremos igualmente cultos pero más felices.

\section{El tío rico}

De entrada y como estamos en el Huila a este juego le vamos a cambiar el nombre se llamará: disfrutemos conociendo al Huila.

Fundamentalmente tomaré 3 aspectos de nuestro departamento: la parte histórica, la cultural y la geográfica.

Los billetes serán diseñados de acuerdo al sistema de numeración Indu-Arábigo, es decir: billetes de a peso (unidades), billetes de 10 pesos (decenas), billetes de 100 pesos (centenas), billetes de 1000 pesos (milenas), etc. y cada uno de estos tendrá una imagen de acuerdo a las temáticas señaladas anteriormente (Ver Figura 1).

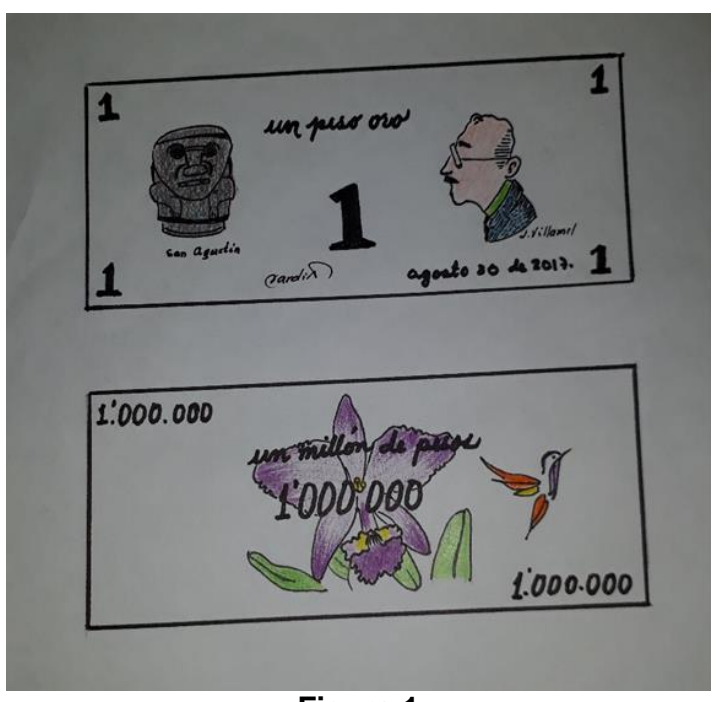

Figura 1

Cada jugador tendrá una cajita que representa un ábaco abierto para que en el organice y ordene los billetes de acuerdo a nuestro sistema de numeración (Ver Figura 2).

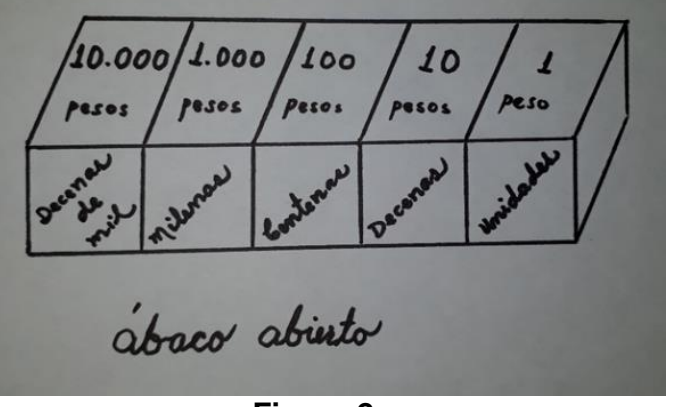

Figura 2

Las tarjetas incógnitas pueden ser las originales. Las tarjetas de propiedad tendrán los elementos señalados y que corresponden al Huila, a saber: nevado del Huila, represa de Betania, desierto de la Tatacoa, parque de San Agustín, 
monumento a la Gaitana, Valle del Suaza, capital cacaotera, ciudad Luz, municipio verde, capital arrocera, capital ganadera, reinado del bambuco, Jorge Villamil, municipio de San Agustín, salto de Bordones, cueva de los Guácharos, Pedro de Añasco, Diego de Ospina y Medinilla, Rumichaca, cuál es el municipio más antiguo, cuántos municipios tiene el Huila, el porqué del nombre Baraya para uno de sus municipios, etc.

Un jugador puede decir cuando está en su turno: voy a comprar una casa en la ciudad luz o me quedo con el rio Magdalena por decir algunas cosas siguiendo las reglas de este juego.

Los dados ya no tendrán puntos sino números y no solo del 1 al 6 sino otros, números naturales y ¿Por qué no números enteros?

Que hay de matemática dentro de este juego: contar, números ordinales, números cardinales, clasificación, sistema de numeración Indu-Arábigo, suma, resta, multiplicación, división, propiedades: clausurativa, conmutativa y asociativa, existencia del inverso y del neutro, todo esto último con respecto a la suma (si juega con 2, 3 o más dados) y unas cuantas cosas más, y qué tal si al tirar dos dados sale: ¿0 y $5,-3$ y $8,-3$ y -3 etc.? Dejemos que el niño jugador tome decisiones aunque algunos conceptos matemáticos que posiblemente aparezcan no sean todavía materia de estudio. Él debe ir familiarizando con algunos de ellos y podemos si es necesario indicarles como una nueva regla del juego que, cuando aparezca un número como el -3 debe devolverse y no avanzar como se hace cuando sale el 5 por ejemplo.

El juego permite también conocer aspectos del Huila como los señalados primeramente y de esta manera tenemos otra opción diferente para la enseñanza y el aprendizaje. La memorización de: hechos, fórmulas, algoritmos, tablas de multiplicar, etc., vamos echándolos a la cesta de la basura y creo que después, éstos, ni si siquiera serán elementos reciclables.

También es importante que se vayan manejando algunos elementos del lenguaje al leer, asimilar y reflexionar sobre la información que nos presenta el juego incluyendo desde luego las reglas del juego.

En definitiva un juego puede permitir retomar varias áreas del conocimiento y al jugarlo varias veces y todos los días, se van los jugadores-alumnos apropiando de una cultura más rica y además los aprendizajes serán más duraderos en cuanto se guardará en la memoria de otra manera más eficaz, eficiente y placentera, diferente a la memorización.

Pero ojo amigo lector, lo señalado por los intelectuales que hoy menciono y otros tantos, no se pueden echar al olvido porque de sus aportes, podremos sacar un 
mejor provecho de lo que hasta aquí he señalado.

Considerando otros juegos que incluyen los dados, que les parece si le echamos un vistazo a los sólidos platónicos, se nos presentan aquí otros modelos para los dados tradicionales y en ellos podemos colocar varios conjuntos de números diferentes a los números naturales a saber: los enteros, los fraccionarios, los decimales, etc. (Ver Figura 3).

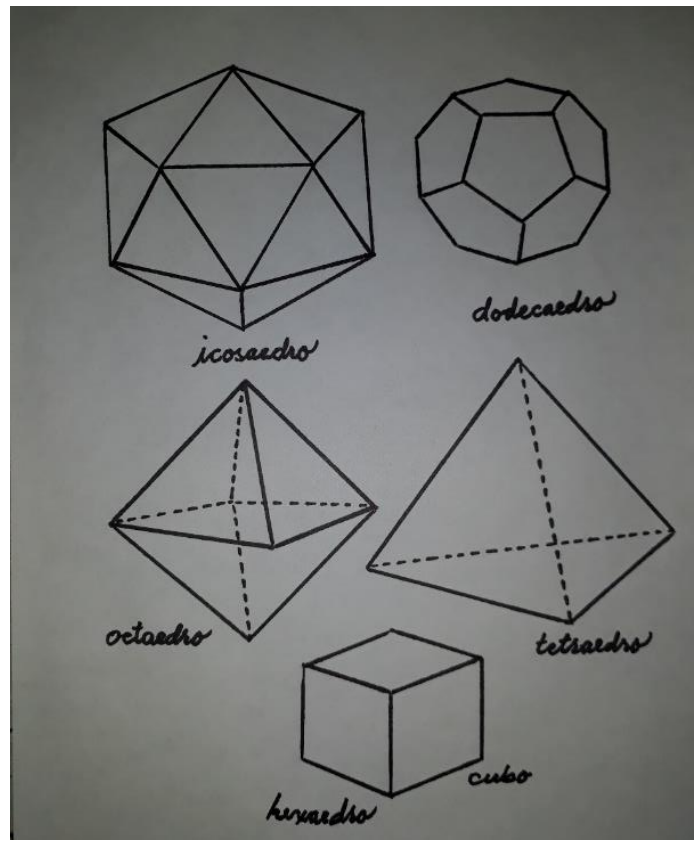

Figura 3

Juguemos solo a tirar 1, 2, 3, etc., dados a la vez. Dejemos que el niño analice y proponga algo sobre la siguiente situación que se obtiene al lanzar 2 dados: $i^{1 / 2+1 / 4}$; $1 / 2+1 / 3 ; 2 / 5-7 / 6 ; 1 / 3+2 / 5 ; 2-3$, etc.?

En el juego de la rana (Ver Figura 4), juguemos a ella practicando el conteo con los números naturales (de 1 en 1 , de 10 en 10 , de 100 en 100 , de 2 en 2, de 3 en 3, etc.). ¿Qué ganaremos con ello al llegar a la multiplicación y división entre números naturales? Aquí hay tema para otras notas y se debe señalar el verdadero potencial del conteo dentro de la matemática.

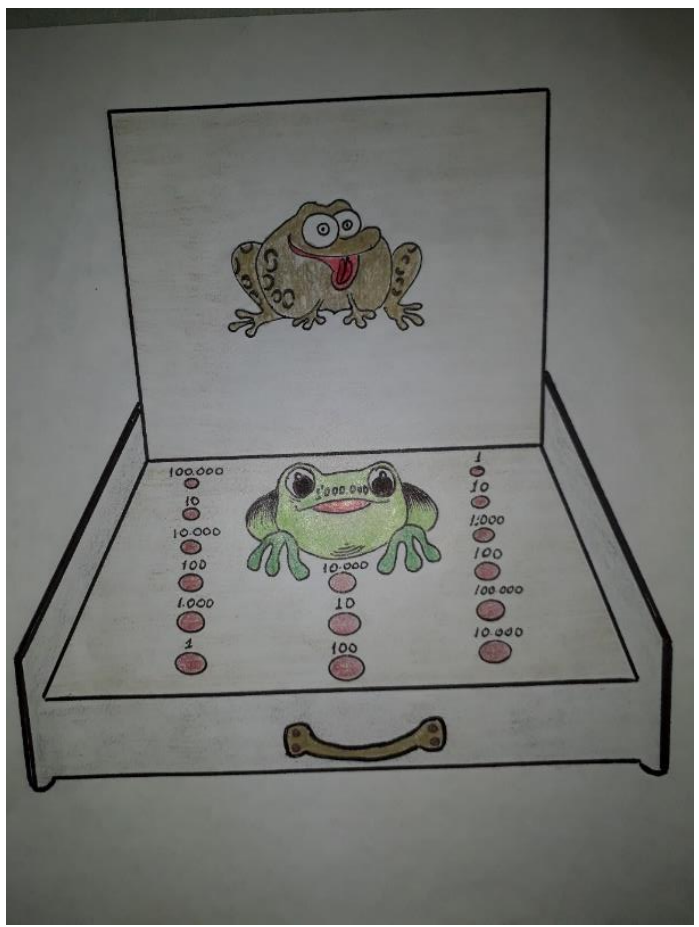

Figura 4

El llamado final consiste en mirar otros juegos, revisarlos, acondicionarlos y que vayan desplazando en gran medida las clases tradicionales.

Lo que aquí les presento son simplemente algunas ideas que de ninguna manera tienen que tomarse al pie de la letra, lo interesante consiste en compartir con nuestros estudiantes diversas propuestas metodológicas para las clases o para las evaluaciones y para unas cuantas cosas más, en últimas puede tomarse como un 
simple despertar hacia la consolidación de otros espacios en los procesos de enseñanza y aprendizaje, más ricos en sueños, felicidad, asombro, que le permitan al aprendiz gozar mucho más su paso por esas frías paredes de la escuela.

Solo me resta aquí dejar el siguiente homenaje para el gran matemático Jesús Hernando Pérez, él algún día me comentó: “en primaria prácticamente todo se reduce a contar y medir", aunque medir, es contar (nota del autor). Esto indudablemente es tema de otros artículos, como ya lo había mencionado.

La inspiración, el fantástico deseo de escribir, el contar los sueños, las anécdotas y las historias de vida, aún me acompañan

\section{Referencias}

Cordero, L. H. (1.997). Canción para matar el miedo. Cooperativa editorial magisterio. Santafé de Bogotá.

Huizinga, J. (1.990). Homo Ludens. Alianza editorial S.A. Madrid.

Jiménez, C. A. (1.996). La Lúdica como experiencia cultural. Cooperativa editorial magisterio. Santafé de Bogotá. 